\title{
SHOULD YOU PUBLISH IN ELECTRONIC JOURNALS?
}

\section{Aldrin E. Sweeney}

\begin{abstract}
The rapid growth of information and communication technology since the early 1990s has greatly influenced the accessibility of information on a global level and also has played a critical role in restructuring the mechanisms by which specialized academic knowledge is validated, distributed, and made available to consumers. The primary mechanism for validation and distribution of academic knowledge is that of peer-reviewed publication, and it is this mechanism and its intersection with Internet-based electronic publishing that constitute the focus of this study of attitudes toward scholarship presented in electronic formats.
\end{abstract}

KEY-WORDS:Electronic journals ; Information and communication technology ; digital library 
SCHOLARSHIP, PUBLICATIONS, AND THE ACADEMIC REWARD SYSTEM

"Scholarship" is the "fund of accumulated knowledge and learning in a defined field or discipline." It also refers to the process of contributing to specific bodies of knowledge (adapted from MerriamWebster, 1976). The academic reward system is structured to encourage quality scholarship primarily in the form of publications -- formal contributions to the knowledge base in specific fields, which are intended to be widely read and acknowledged by others in those fields. Scholarly publications are produced by researchers as part of their jobs, and at most universities and research organizations publications count significantly toward salary and job security (Varian, 1997). The quality and extent of academic publications in recognized academic or professional journals typically are a primary measure of a scholar's value and evidence of eligibility for promotion and tenure. However, all publications are not equal, and competition to publish in top-ranked journals is often intense. According to Varian (1997).

The demand for space in those journals is intense because they are highly visible and widely read. Publication in a top-flight journal is an important measure of visibility. In some fields, citation data has become an important observable proxy for "impact." Citations are a way of proving that the articles one publishes are, in fact, read.

Premier paper journals can take from one to two years to go through the process of formal submission, acknowledgement of receipt, refereed peer review, modifications and revisions, formal notice of acceptance, and printing and distribution. Given that faculty promotion and tenure requirements often emphasize publication volume in a limited period of time (with institutional rankings also based on numbers of publications by their respective faculties; see Budd 1995), publishers maintain that they are responding to faculty demands as new journals are created and existing journals increase in size (Resh, 1998). Dixon (1997) suggests that the pressure to publish can be marginally alleviated by easy and straightforward electronic submission and refereeing of papers, fast turn-around times at publishers, strong online communities and the free delivery of suites of software that aid the compilation of a paper (see Resh, 1998 for a comprehensive analysis of major issues associated with the transition from paper to electronic academic publishing). Somewhat whimsically (and perhaps even prophetically), Whisler (1997) has even suggested that "... if left to their own devices, scholars might construct an electronic world in which both publishers and librarians see their roles reduced or eliminated."

\section{E-JOURNALS A GROWING TREND}

Scholarly communication is a critical component of academic research and the generation of new knowledge. Scholarly communication provides the rationale for conferences, conventions, symposia, colloquia, and other regularly scheduled meetings of scholars in a discipline. In particular, scholarly communication is the primary function of publications in academic journals; it is important to know what other researchers in your discipline are doing so as to improve your professional and academic efforts and to avoid duplicating theirs. Hence, scholars 
generally want access to a broad range of academic journals (Varian, 1997).

The rapid growth of information and communication technology since the early 1990s has greatly influenced the mechanisms of knowledge distribution by university faculty and other researchers. In my primary discipline areas -- science education, chemistry, and biochemistry -there are more than one hundred academic journals that are partially or fully electronic from each of the major publishers: Elsevier Science, Taylor \& Francis, Wiley Interscience, and Kluwer Academic Publishers. The American Journal of Science (founded in 1818 and the oldest scientific journal in the United States to be published continuously) currently lists contents and abstracts of its 1995-1999 issues electronically, and the American Journal of Mathematics (the oldest mathematics journal in the Western hemisphere, in continuous publication since 1878) has electronically published full text research papers since 1996.

As Kling and Covi (1995) write,

It does not take much work to find that the number of e-journals is growing annually and includes fields from theoretical computer science to medieval literature, or to find numerous instances where scholars have learned of new results or studies more rapidly by using electronic media.

The Electronic Journal of Differential Equations, an entirely online publication, describes itself as follows:

The Electronic Journal of
Differential Equations (EJDE) is
dedicated to the rapid
dissemination of high quality

research in mathematics. Research articles are refereed under the same standards as those used by the finest-quality printed journals. Proceedings of conferences and long expository papers (monographs) are accepted at the discretion of the editors (my italics).

It is apparent that this journal has taken great care to emphasize the main advantages which it holds over paper journals -- quicker turn-around times and rapid dissemination of research findings. Great care also has been taken to emphasize the same rigor of peer review associated with traditional paper journals, an issue that will be examined more closely in the following section.

\section{PEER REVIEW : NOT AN ARTIFACT OF PAPER}

There is no special problem of scientific quality control idiosyncratic to the electronic medium, according to Harnad (1982; 1986; 1996), who has written extensively on the topic of academic publishing in electronic journals. Scholars who review articles for electronic journals are equally required to criticize and evaluate the work of their peers before the work is formally legitimized and accepted as a contribution to the knowledge base in a discipline. While there are problems with the peer-review system that will not be addressed here, even Harnad, a wellknown critic of scholarly publishing, maintains (1996),

Like democracy, it has imperfections, but it has no viable alternative, whether on paper or on the electronic airwaves. 
In a comprehensive analysis of recent literature, Ryder (1997) discusses a number of issues associated with peer review in electronic academic journals, including text ownership, the studio/gallery model of peer review, and the notion of plastic texts (also see Roberts, 1999). While a detailed exploration of these issues is beyond the purview of the present study, such considerations are becoming increasingly important in the academic world as debate continues regarding the legitimacy of electronic scholarly journals.

Kling and Covi (1995) indicate that while the number of electronic scholarly journals is growing steadily, they have not yet been fully accepted as legitimate publication outlets by the various scholarly communities. Concerns exist (justified or otherwise) that the integrity of the peer-review process is possibly compromised with electronic journals. Kling and Covi write:

As with paper publications, articles that are submitted to e-journals may be lightly edited or tightly reviewed by an editorial board with strong academic standards. Today, many scholars are confused about the formats and intellectual quality of e-journals. In extreme cases, they feel that e-journals must be of lower intellectual quality than p-journals, because they sense something insubstantial and potentially transient -- ghostly, superficial, unreal, and thus untrustworthy -- in electronic media. In practice, some refereed e-journals publish high quality articles, but they are not well known by their existential critics.
What are the common perceptions and misperceptions of scholars regarding the legitimacy of electronic scholarly journals and the papers they feature? The following sections of this paper will present the perspectives of a group of university administrators and faculty in Florida and also discuss the implications of these perceptions for university faculty in the Florida State University System and in the wider academic community.

\section{METHODOLOGY}

The Florida State University System consists of ten publicly funded universities -- Florida Agricultural \& Mechanical University, Florida Atlantic University, Florida Gulf Coast University,Florida International University, Florida State University, University of Central Florida,University of Florida, University of North Florida,University of South Florida, and University of West Florida (see Florida Board of Regents, 2000).

I compiled the names and e-mail addresses of all top university administrators in the ten institutions: university presidents, provosts/vice presidents for academic affairs and college deans. I also got the e-mail addresses of all faculty members at the University of Central Florida, my institution. I sent an e-mail message to seventy-five of the administrators (and asked them to pass it on to department chairs and others involved in faculty promotion-and-tenure decisions) and to all the faculty members. The message asked them to participate in a study of perceptions of electronic academic publishing, and contained a questionnaire and survey. I assured them that their identities would remain confidential. 


\section{Questionnaire and survey instrument} (Florida SUS administrators \& UCF faculty)

- What formal policies/guidelines exist at your institution (and/or within your respective Colleges and Schools) regarding scholarly publications by faculty on the World Wide Web vs. traditional hard copy academic journals? Do informal policies/guidelines exist, and if so, what are they?

- Have any faculty at your institution (and/or within your respective Colleges and Schools) submitted a tenure/promotion portfolio for consideration featuring electronically published articles or other scholarly work? How was this received?

- Please respond to the following short survey indicating your response to each item, A-D (1=strongly agree; $2=$ agree; $3=$ neither agree nor disagree; $4=$ disagree; $5=$ strongly disagree):

A. The peer-review process is as thorough in electronic journals as with paper (hard copy) journals.
1. 2. 3. 4. 5.

B. Electronic publishing undermines the integrity of academic rigor.

1. 2. 3. 4. 5.

C. Electronically published articles should be counted in the tenure and promotion process.
1.
2. 3. 4. 5 .

D. Issues relating to electronic publication are more important for tenure seeking faculty than for tenured faculty.
1. 2. 3. 4. 5.

Additional data for this study were obtained from the editor of an electronic academic journal in my field who also was contacted via e-mail and asked to contribute his perspectives as a scholar who had established an electronic academic journal in his discipline. All data used in the present study were collected and accessed during February and March, 2000.

\section{DATA ANALYSIS}

A total of sixty-two responses were obtained. Administrator responses totaled thirty-one and included three university presidents, two provosts/vice-presidents for academic affairs, sixteen college deans/associate deans, and ten department chairpersons. The administrator responses represented nine (out of ten) universities in the Florida state university system. 
Thirty-one responses also were obtained from faculty at the University of Central Florida.

The survey responses (statements A-D) from administrators and faculty were quantitatively compared and analyzed as an entire data set and by disaggregation into administrator and faculty responses, respectively. Qualitative data obtained from answers provided to the freeresponse questions and from additional explanatory narrative provided by respondents (both administrators and faculty) were used to enrich and further clarify the interpretive section of this study.

TABLE 1 - Survey responses

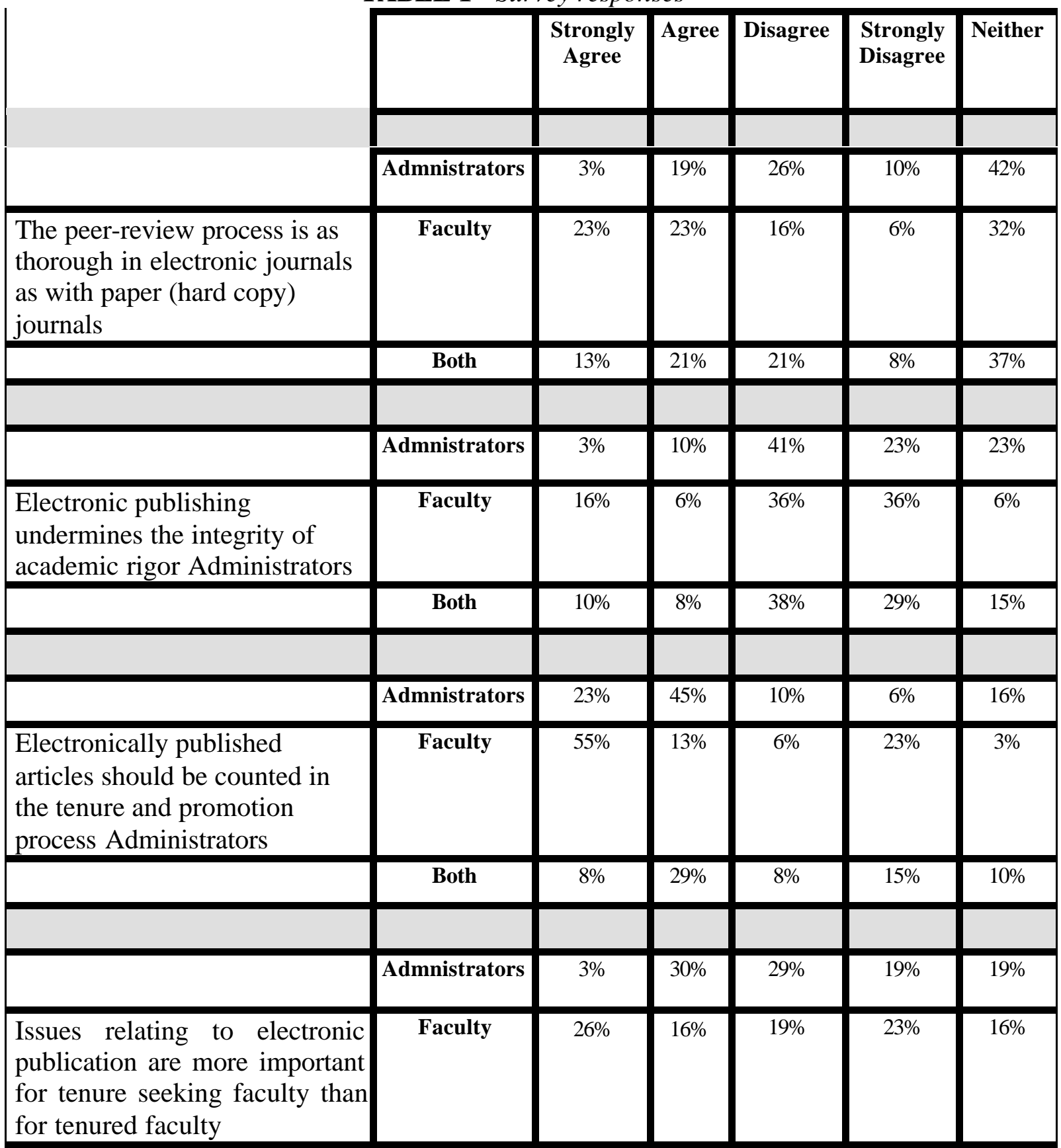


ARTICLE

\begin{tabular}{|l|c|c|c|c|c|c|}
\hline & Both & $15 \%$ & $23 \%$ & $23 \%$ & $21 \%$ & $18 \%$ \\
\hline & Admnistrators & $23 \%$ & $45 \%$ & $10 \%$ & $6 \%$ & $16 \%$ \\
\hline $\begin{array}{l}\text { Electronically published } \\
\text { articles should be counted in } \\
\text { the tenure and promotion } \\
\text { process } \\
\text { Administrators }\end{array}$ & Faculty & $55 \%$ & $13 \%$ & $6 \%$ & $23 \%$ & $3 \%$ \\
\hline & Both & $38 \%$ & $29 \%$ & $8 \%$ & $15 \%$ & $10 \%$ \\
\hline & Admnistrators & $3 \%$ & $30 \%$ & $29 \%$ & $19 \%$ & $19 \%$ \\
\hline $\begin{array}{l}\text { Issues relating to electronic } \\
\text { publication are more important } \\
\text { for tenure seeking faculty than } \\
\text { for tenured faculty }\end{array}$ & Faculty & $26 \%$ & $16 \%$ & $19 \%$ & $23 \%$ & $16 \%$ \\
\hline & & & & & & \\
\hline
\end{tabular}

\section{DISCUSSION}

Statement A : The peer-review process is as thorough in electronic journals as with paper (hard copy) journals

Analysis of administrator and faculty responses to this statement indicated that the respondents were approximately equally divided in their perspectives on this issue with $37 \%$ who neither agreed nor disagreed, $34 \%$ who either agreed or strongly agreed, and $29 \%$ who either disagreed or strongly disagreed. While there appears to be some measure of equilibrium between the given responses, the qualitative data submitted by the respondents neither agreeing nor disagreeing indicate that many are simply unaware of or unfamiliar with the review process that occurs in electronic journals. This is illustrated by the following comments in response to this statement:
Don't know -- if they are just electronic versions of the traditional journals, there should be no difference (Florida SUS dean).

I serve as a reviewer for two scholarly publications in the field of nursing, one traditional and one on-line. The review process for both publications appears to have similar rigor. In the School of Nursing, we report our publications according to whether or not they are in peer-reviewed journals. I imagine it would be the same for on-line journals (UCF faculty).

A comment by a faculty member offers a possible explanation for the seeming uncertainty concerning the peer-review process in electronic journals, but also suggests that such uncertainty is not always warranted: 
As this is relatively new, I think it may still suffer from external perceptions of being less rigorous than the more conventional journal review process. This becomes a moot point, however, when applied to a mainline journal that issues BOTH electronic and paper-based versions of their publication (UCF faculty).

The following constructive critique of the survey instrument used in the present study provides a telling insight into current perceptions concerning the validity of the peer-review process in electronic versus paper journals:

Unfortunately, your survey does not differentiate among electronic journals, but all e-journals are not equivalent in many ways. You really need to define very explicitly and specifically what you mean by "electronic journal" in order to have a meaningful survey. Otherwise, respondents are free to assume you mean either the worst possible or best possible sense of the term, or anything in between. Some are electronic versions of paper journals, some are peer reviewed, some are editorreviewed, some are not selectively screened at all as far as I can tell. Some are literally just electronic embodiments of precisely the same sort of journal offered in paper (this is true for most IEEE electronic journals, for example), by design as rigorous and selective as an ordinary paper journal. There is, however, also a great deal of anecdotal material to the effect that knowing one of the site maintainers almost guarantees acceptance. Some articles I have seen seem to be concerned principally with demonstrating what can be done with the technology or with what a particular person can show that he or she can do, but lacking in the depth, length, rigor, or substantive relevance that we expect of paper peer-reviewed journals (UCF faculty).

Related issues concerning technology were also evident. A dean noted that peer review was not necessarily a concern with certain forms of electronic publications; that dean also raised an important concern with regard to the currency of published research in particular discipline areas:

Do you include CD-ROM publications as electronic ones? I believe these are becoming very common as conference proceedings. They have the advantage of going through the normal reviewing process, so no real stigma. In the sciences, there is talk of having professional societies certify research accomplishments because even electronically refereed publications are normally old news. So many researchers offer their results via web pages, etc., that publications are too dated to be worthwhile in high-tech fields (Florida SUS dean).

A faculty member spoke to the complexity of the technological issues:

To the best of my knowledge, there are no formal policies/guidelines within the College of Business Administration concerning scholarly publications by faculty on the World Wide Web vs. traditional hard copy academic journals. I also am unaware of any informal 
policies/guidelines that may exist. This topic was the subject at a recent conference I attended. There were faculty concerned with the fact that the conference proceedings were on a CD versus hard copy. One faculty member stated that, because they were currently undergoing a review by their accreditation organization, he asked one of the officials if the $C D$ version was acceptable. He was told that all he had to do was print the cover, table of contents and the article itself from the $C D$ and that would be the equivalent of a hard copy (UCF faculty).

Since some electronic journals utilize the peer-review process while others do not (a situation true of paper journals, too), several respondents wrote that they could not be definitive about whether the process was the same in both media:

In some cases, yes, but in some not. (Florida SUS dean).

This needs to be assessed for each case; cannot give a generic response (Florida SUS department chair).

Many of those who felt unable to provide an answer (from the five available responses) responded by indicating "unknown" to this statement. These responses were categorized as response "3" (neither agree nor disagree) for the purpose of data analysis.

Further analysis indicated higher levels of uncertainty from administrators compared to faculty regarding the equivalency of the peer-review process in e-journals and p-journals; $46 \%$ of faculty either agreed or strongly agreed, compared to $22 \%$ of administrators agreeing or strongly agreeing with this statement. The responses by administrators to the question of whether any formal or informal policies existed at their institutions regarding faculty publications in electronic journals were particularly indicative of this uncertainty:

Within our department we don't have any policies regarding publication in Web-based journals vs. hard copy -- but assuming that they were considered scholarly, and were appropriately refereed, I don't think we would have a problem (Florida SUS department chair).

None -- yet (Florida SUS president, 1).

None that I am aware of at this time (Florida SUS president, 2).

No specific policies, but the expectation is that any such publications must have the same rigorous peer review as hard copy (Florida SUS dean).

This is primarily a departmental issue. All of our departments have formal guidelines for promotion and tenure which spell out the departmental requirements for promotion and tenure. Most of these documents have NOT specifically addressed this issue. At the college level, we have no formal, written guidelines. However, in all informal discussions, we encourage that full credit be given for electronic publications as appropriate to the discipline (Florida SUS dean). 
We have left this discussion up to the academic units (Florida SUS provost).

The following succinct response was representative of those faculty indicating their agreement with the statement:

Peer review is peer review. Different journals have different standards (UCF faculty).

\section{Statement B : Electronic publishing undermines the integrity of academic rigor}

Analysis of the available data suggests a high level of overall consensus concerning the academic rigor of electronic publications and the process of electronic publishing. Sixty-seven percent of all respondents indicated disagreement or strong disagreement with the statement; when disaggregated into administrator and faculty responses, 64\% of administrators disagreed or strongly disagreed compared to $72 \%$ of faculty disagreeing or strongly disagreeing with this statement. This consensus is somewhat surprising given the responses to the first statement in the survey soliciting respondents' perspectives concerning the equivalency of the peerreview process in electronic journals vs. paper journals. It is, however, important to note the majority of respondents' comments indicating that their disagreement with this statement was contingent upon the demonstrated quality of the peer-review process associated with electronic publications:

I see nothing inherently different about electronic publications; the refereeing process is the key issue. We need to have a system that certifies peer acceptance regardless of publication medium (Florida SUS dean, 1).

In my mind the issue is not the medium, but rather the message. The two key parameters are (a) the extent to which the publication has undergone effective peer review and (b) the impact of the publication on the scholarly community, i.e., who is reading the article and to what degree is their scholarship being impacted by that work (Florida SUS dean, 2).

With any scholarly product, we attempt to gauge the rigor of the refereeing/evaluation process and the quality of the outlet/journal before deciding how much weight to accord the product (Florida SUS dean, 3).

Not necessarily; again depends on the recognized quality of the journal and rigor of peer review (Florida SUS department chair).

A president in the university system said that the decision should be made by the provost or vice president for academic affairs at an institution, as long as quality is ensured:

The Provost's should be the definitive voice on this question. I don't think we have come up with formal guidelines. From my perspective, the form of publication is not important. It is the quality of the editors and referees, and the selectivity that matter (Florida SUS president).

One faculty member who disagreed strongly that electronic publishing undermines the integrity of academic 
rigor raised the point that many established peer-reviewed paper journals now publish in hard copy and electronic formats and have not changed their standards:

Poppycock! Try getting an article published in a major journal that also has an electronic version of it and see how rigorous that process can be! (UCF faculty).

Responses indicating either agreement with the statement, or "neither agree nor disagree" were typified by the following statements:

... there is no current departmental policy for publishing in electronic journals. [My department chair] said that while he has no problem with electronic publication per se, he feels the department should discuss the issues relating to rigor of the review process for electronic journals (UCF faculty).

As of now, they (electronic publications) really don't count much. They are not respected and are probably considered no better than a conference paper (UCF faculty).

I believe that any serious suggestion to accept Internet publications as replacements for any printed archival journal is a waterdown of academic rigor. Yes, there are journals that we can access through the web. But those journals have hard copy printed counterparts where any publication has to go through review. As you can see on our library's home page, there is a site called "electronic resources." Journal articles can be downloaded from there in PDF format. You cannot add, delete, or edit in any way any part of those articles in PDF format. You therefore can see that those journal editors or publishers do not want to sacrifice their reputation for providing a credible academic forum. The reason that they are on the web is that it is convenient for the dissemination of knowledge from rigorous intellectual pursuit, not that they want to appeal just to follow the high tech gimmick. Anybody serious about learning can always find those articles even if they are not posted on the web. But not everything posted on the web deserves credit. I do not think one would just get on the web to find posted medical advice in placement of a physician, except possibly those who are constantly looking for an elixir or something that would double his masculinity overnight (UCF faculty).

Few faculty in my program have, to date, published in such journals. However, in discussion with colleagues I get the impression that online publications are viewed with a degree of suspicion regarding their value as "real" scholarship (UCF faculty).

\section{Statement C : Electronically published articles should be counted in the tenure and promotion process}

University administrator and faculty perspectives on whether electronic publications are regarded as "real" scholarship undoubtedly hold important implications for the tenure and promotion process and the academic reward system. Sixty-seven percent of all respondents in the study agreed or strongly agreed that 
electronically published articles should be counted in the tenure and promotion process. Disaggregation of the data into administrator and faculty responses indicated that while there was a high level of general agreement for administrator and faculty responses to this statement (both at $68 \%$ ), only $6 \%$ of administrators strongly disagreed with the statement, compared to $23 \%$ of faculty. Faculty respondents were much more definitive in their responses to this statement, with only $3 \%$ indicating a "neither agree nor disagree" response compared to $16 \%$ of administrators. Unfortunately, faculty who disagreed or strongly disagreed with the statement did not offer comments about their choices. Fortunately, a majority of administrators provided comprehensive explanatory narrative to their survey responses. As one administrator put it,

\section{[Electronically published articles} should be counted in the tenure and promotion process] .. . subject to the same criteria as paper journals on review process and acceptance (Florida SUS provost).

In response to the question of whether any faculty at the respondent's institution had submitted a tenure and promotion portfolio for consideration featuring electronically published articles, the same administrator wrote:

Yes and it was well received, but documentation accompanied it on the acceptance rate and review process (Florida SUS provost).

While no formal policies or guidelines currently exist in the Florida state university system, several informal policies are in place at different institutions, and within different colleges and program areas:

In response to the discursive questions at the beginning of your e-mail: We do not have formal policies or guidelines concerning $e$ journals specifically. Our informal policy is to grapple with the question as it comes up in promotion and tenure decisions, yearly evaluations, and promotion and tenure progress reports. To the best of my knowledge, no promotion and tenure portfolio has "featured" e-journals, though one recently included a reference or two, however the overwhelming mass of supporting material was in peerreviewed print media. In another case, though, a junior faculty in the process of working toward tenure has included e-journals as a significant portion of his/her accomplishments. As far as I can tell, there is not enough documentation to establish that those entries are comparable to peer-reviewed print journals (UCF faculty).

I believe that for any new publication regardless of medium, the burden would be on the candidate to demonstrate the quality of the journal (Florida SUS dean, 1).

In my experience, no faculty member has submitted a tenure and promotion portfolio which was heavily weighted toward electronic publication. Certainly, faculty have published electronically, but this has generally been backed up with substantial print publications in high-quality refereed journals or 
with selective publishers (Florida SUS dean, 2).

Only a small number of such publications have appeared on recent portfolios. Because these have been only a small part of the candidates' total portfolios, they have been accepted without comment or concern (Florida SUS dean, 3).

Everything counts, but some count more than others; the question probably should be do they count as much, in which case my answer still is "it depends", just as some journals are more prestigious (i.e., count more) than others (Florida SUS dean, 4).

Judging from comments made by our dean at a recent tenure and promotion meeting, it was unclear as to what position the dean really takes. If there are policies, I must have missed seeing them. A void that needs correcting, for sure! (UCF faculty).

Interestingly, the data obtained during the course of this study suggest that scholars attempting to publicize their work in specific discipline areas (such as communication, or computer information systems for example) may play a critical role in determining whether electronic publications become more widely regarded as legitimate scholarly outlets contributing toward promotion and tenure:

Faculty in new media and interactive areas are submitting work to electronic scholarly publications. Such outlets are gaining respectability and acceptance vis-à-vis annual evaluations and promotion and tenure. Portfolios containing a mix of traditional and electronic scholarly publications are becoming increasingly common, especially in technology-oriented fields. Portfolios containing only such work would not be considered sufficient, however (Florida SUS dean, 5).

Respondents who agreed offered further arguments supporting the idea that electronically published articles should be counted in the tenure-and-promotion process:

It is important to note that it is the journal/publication/proceedings, etc. that determines the value of the publication from a tenure/promotion situation, not how it is published. If the journal is electronic, but widely accepted as a quality publication, it won't matter if it is published electronically or in hard copy. The future may very well see mainline journals published only electronically (UCF faculty).

There are no formal policies per se regarding online publications. Their relative newness and the lack of familiarity of many faculty toward the rigor of the review process hamper any consensual acceptance of them as legitimate scholarly outlets. However, the lack of formal policies also suggests that they would not be rejected out of hand at merit and promotion considerations (Florida SUS dean, 6).

I am unaware of any of my colleagues submitting a 
tenurelpromotion portfolio for consideration featuring electronically published articles or other scholarly work. I personally believe it would be found acceptable, however (UCF faculty).

\section{WHY NOT? (UCF FACULTY)}

\section{Statement D: Issues relating to electronic publication are more important for tenure seeking faculty than for tenured faculty.}

Administrator and faculty responses to this statement appeared to be approximately equally distributed, with $44 \%$ of respondents either in disagreement or strong disagreement, $38 \%$ in agreement or strong agreement, and $18 \%$ neither agreeing nor disagreeing. While the quantitative data appear to indicate that at least $38 \%$ of those surveyed did not believe this issue to be as important for tenured faculty, an analysis of the qualitative data shows that this is potentially misleading. Analysis of the qualitative data implies that this statement was somewhat ambiguously worded. As a tenure-seeking member of the faculty, I think that issues relating to electronic publication are more important for tenure-seeking faculty. I assumed that those who disagreed with the statement would think that it is more important for tenured faculty. However, as I analyzed the written responses I realized that many of those who disagreed with the statement were expressing the thought that it was equally important for tenure-seeking and tenured faculty. The following responses to the statement are illustrative:

Not true; equally important for both (Florida SUS dean, 1).
In these days of academic accountability measures, ALL faculty, both tenured and untenured must continue to publish. If it is in traditional or electronic journals is not the issue! (UCF faculty).

Strongly disagree -- for everyone (Florida SUS dean, 2).

\section{Strongly disagree -- should be the} same for both (UCF faculty).

There were, however, a few responses indicating that these issues might be of more pressing concern to tenure-seeking rather than already tenured colleagues. Two examples are representative:

Please keep in mind that people who are seeking tenure will probably have to deal with many more years of electronic publications -- and many of the people who make the tenure rules probably did not and will not for as many years in the future (UCF faculty).

Probably so, both because they are more at risk and because they might be more likely to embrace electronic publications while veteran colleagues have reservations (Florida SUS dean, 3).

\section{PERSPECTIVES OF AN ACADEMIC E-JOURNAL EDITOR}

Dr. John Cannon, University of NevadaReno, is the editor of the Electronic Journal of Science Education, a free, entirely online, blind peer-reviewed academic journal. He responded to a set of questions and gave permission for their publication. 
What caused you to first consider electronic publication of scholarly work in your academic field?

Speed of reviews and publication. The thoroughness of electronic reviews is much clearer and more comprehensive than with paper reviews.

Were there any professional obstacles to this decision (e.g. from colleagues, mentors, prominent persons in your academic discipline)? Please elaborate.

Sure, many of my colleagues said (before my tenure and promotion), "O.K., enough with this electronic publishing. Stick to the paper journals". Well, they've had to eat their words, at least at my institution where my promotion and tenure was a sort of test case with the campus promotion and tenure committee. All they asked (reportedly) was "Are these journals/articles peer reviewed?" That was it.

A. The peer review process is as thorough in electronic journals as with paper (hard copy) journals.

Strongly agree. Even more so!

B. Electronic publishing may undermine the integrity of academic rigor.

Strongly disagree. Can only make it more rigorous.

C. Electronically published articles should be counted in the tenure and promotion process.
Strongly agree. To cite from the TV program Star Trek: The Next Generation -- "We are the Borg. Resistance is futile. You will be assimilated".

D. Issues relating to electronic publication are more important for tenure seeking faculty than for tenured faculty.

Strongly agree. Unfortunate, but probably true. However, it is changing with each passing day.

While the responses to statements A-D may have been somewhat predictable for the editor of an electronic academic journal, the statement made here concerning the greater rigor of the peerreview process in electronic journals very much challenges popular opinion and provides an intriguing counter to many of the perspectives reported in this study.

\section{APPLICABILITY}

Thirty-one university administrators across Florida (representing nine of the ten state universities) and thirty-one faculty members at the University of Central Florida may not constitute a statistically significant sample, but their opinions are indicative of how the traditional definitions of "scholarship" are now being reassessed and even challenged within the academic community. The rich qualitative data in the written narratives submitted by university administrator and faculty respondents compensate for the small sample. Others might want to conduct a modified, longitudinal replication of the study allowing for a much longer dataaccess period and survey all Florida State University System administrators and 
faculty (or a statistically representative sample) to build on the emergent findings and interpretations of the present study. The perspectives of other editors of entirely or partially electronic scholarly journals -- representing a wide range of academic disciplines -- also would provide useful additional insights into the challenges and successes associated with scholarly productivity via this medium.

Whither do we go from here? The comments of one respondent in this study suggest that the topics explored here may well become a stimulus for further serious discussion at institutions of higher education, both within and outside of Florida:

This is an interesting way to collect data although some may be concerned about the confidentiality of their responses. I hope this reaches you and that others take the time to complete the survey. This has potential for becoming an important issue, especially for new faculty attempting to make a career in academe.

Guidelines and policies relating to electronic publishing, promotion, and the awarding of academic tenure may soon be negotiated by university faculty trade unions such as the United Faculty of Florida in determining the professional rights and obligations of university professors. Whether or not that happens, this study suggests that the Florida State University System needs to explore

Certainly there are universities and other institutions of higher learning that acknowledge electronic scholarly publication in the tenure-and-promotion process. In fact, during the literature review for this study I discovered a formal policies regarding electronic scholarly publication. Respondents pointed out that there were not policies, that they had to "grapple with the question as it comes up." One respondent said the lack of a policy was "a void that needs correcting." As the number of electronic journals grows, and as more faculty members publish in them, the demand for a fair, equitable, and clear policy will also grow.

That pressure will be felt beyond the Florida State University System, too. However, this study does not cover all the issues that must be addressed. The study described here was performed only in one state and only in the context of public universities: How do issues relating to electronic publishing differ or compare at Florida's private universities? At public and private universities across the country? At other non-university sites such as governmental research laboratories and private industries also engaged in knowledge production? Findings and implications of the present study certainly seem to support the argument that "once a technology has been incorporated into the patterns of daily life, it is impossible to turn the clock back to the cultural patterns of life that existed before the adoption of the technology" (see Bowers, 1998, p. 76). Electronic scholarly publishing is challenging to academia because it affects the intellectual interests and preoccupations of academic disciplines and their gatekeepers (see for example Kuhn, 1970, pp. 176-178).

pertinent memorandum, 1999-2000 Academic Reappointment/Promotion Instructions (June 10, 1999) http://www.rutgers.edu/oldqueens/instruct doc sent to provosts, deans, directors, and department chairs at Rutgers 
University by the Vice President for Academic Affairs (Seneca, 1999). The memorandum specifically mentions electronic publications (both refereed and non-refereed) as acceptable evidence of scholarship and explains how to reference them:

3. Journal articles (refereed). (Give title, journal, date, page numbers and list of authors as it appears in the publication.)

4. Journal articles (not refereed). (Give title, journal, date, page numbers and list of authors as it appears in the publication.

5. Electronic publications (refereed). If not listed under \#3 above, give title of publication, journal or other applicable name, network citation, e.g., uniform resource locator (URL), date, approximate number of pages, and list of authors. Indicate if the publication is permanently archived.

6. Electronic publications (not refereed). If not listed under \#4 above, give title of publication, journal or other applicable name, network citation, e.g., uniform resource locator (URL), date, approximate number of pages, and list of authors. Indicate if the publication is permanently archived.

1999-2000 Academic Reappointment/Promotion Instructions, Page 31

It is interesting to note that this prestigious institution openly acknowledges the scholarship associated with electronic publications, while similarly prestigious universities in Florida, according to my survey, do not do so.

Suggestions for future studies in the Florida State University System

Many variables in the Florida system may be explored relating to the acceptance of electronic academic publishing in assessments of scholarship and eligibility for promotion and tenure:

- Florida's ten state universities are classified in three categories: comprehensive (four primarily undergraduate teaching institutions); research II (three rapidly expanding urban research universities); and research I (the three most mature and comprehensive research institutions in the state). How do administrators differ in their publishing expectations, correlated by institution category?

- Which universities -- or departments within universities -- actively encourage or discourage submission to electronic scholarly publications? What are their reasons? How does that correlate with concern about academic equity?

- Do administrators and faculty members differ in their acceptance of 
papers in electronic scholarly publications with regard to tenureand-promotion decisions?

- Do tenured and non-tenured faculty members differ in their opinions of the validity of electronic scholarly publications?

- Do administrators, non-tenured faculty members, and faculty members in different disciplines differ in their opinions of the validity of electronic scholarly publications?

- Does increased access to and familiarity with technology influence the type and extent of research in which faculty engage? Do faculty with less access and familiarity run the risk of not "keeping up" with the latest developments in their respective disciplines? (see Roberts, 1999).

\section{CONCLUSION}

Ongoing discussion and active research regarding these issues in the academic world of the 21 st century must continue if we hope to improve the quality and relevance of academic scholarship, not only in the Florida State University System, but in the wider academic community also. Even without further study, the Florida State University System needs to come up with guidelines and policies relating to electronic publishing, promotion, and the awarding of academic tenure. The increasing reliance on electronic journals by researchers, the proliferation of titles in cyberspace, and the inability to turn the clock back to a paper-only world indicates the need. The conflict scholars face when deciding whether to seek a seemingly speedy route to publication or a slow (but possibly more valid) route is not one that encourages the spread of knowledge. Only a clear policy (no matter which side it comes down on) can rectify this ambiguous situation.

The author gratefully acknowledges the assistance of Dr. Richard Cornell (Professor, Instructional Systems, University of Central Florida; President, International Council for Educational Media) in the conceptualization and preparation of this article. The author also wishes to thank Hillary Sweeney and Nadine Barrett for their valuable assistance in the data-analysis section of this study.

\section{REFERENCES}

C.A. Bowers. 1998. Toward a balanced perspective on the educational uses of computers: Advantages, myths, and the responsibilities of educators. International Journal of Leadership in Education, 1(1), 75-83.

J.M. Budd. 1995. Faculty publishing productivity: An institutional analysis and comparison with library and other measures. College and Research Libraries, 56, 547-554.

A. Dixon. 1997. Electronic publishing and the academic community: A publisher's perspective. In Ian Butterworth's (Ed.), The impact of electronic publishing on the academic community (Session 1: The present situation and the likely future). International Workshop organized by the Academia Europaea and the WennerGren Foundation,

Wenner-Gren Center, Stockholm, Sweden, April 16-20, 1997. [Online]. Available:

http://tiepac.portlandpress.co.uk/books/on line/tiepac/session1/ch2.htm 
Florida Board of Regents. 2000. Florida Board of Regents: University information. [Online]. Available: http://www.borfl.org/univ_info/unitour.as $\mathrm{p}$

S. Harnad, Ed. 1982. Peer commentary on peer review: A case study in scientific quality control. NY: Cambridge University Press.

S. Harnad. 1986. Policing the paper chase. (Review of S. Lock, A difficult balance: Peer review in biomedical publication.) Nature, 322, 24-5.

S. Harnad. 1996. Implementing peer review on the Net: Scientific quality control in scholarly electronic journals. In R. Peek \& G. Newby's (Eds.), Scholarly publication: The electronic frontier ( $\mathrm{pp}$. 103-108). Cambridge, MA: MIT Press. [Online]. Available: ftp://ftp.princeton.edu/pub/harnad/Harnad /HTML/harnad96.peer.review.html

R. Kling and L. Covi. 1995. Electronic journals and legitimate media in the systems of scholarly communication. The Information Society, 11(4), 261-271. [Online]. Available: http://www.ics.uci.edu/ kling/klingej2.ht $\underline{\mathrm{ml}}$

T.S. Kuhn. 1970. The structure of scientific revolutions (2nd edition). Chicago, IL: University of Chicago Press.

Merriam-Webster. 1976. Webster's new collegiate dictionary. Springfield, MA: Author.

V.H. Resh 1998. Science and communication: An author/editor/user's perspective on the transition from paper to electronic publishing. Issues in Science \& Technology Librarianship, 19.
[Online].

Available:

http://www.library.ucsb.edu/ist1/98-

summer/article3.html

P. Roberts. 1999. Scholarly publishing, peer review and the Internet. First Monday, 4(4). [Online]. Available: http://firstmonday.org/issues/issue4_4/pro berts/index.html

M. Ryder. 1997. The peer review process: Excerpts from major articles. [Online]. Available:

http://www.cudenver.edu/ mryder/peer/p eer review.html

J.J.Seneca. 1999. Memorandum to Provosts, Deans, Directors, and Department Chairs (1999-2000 Academic Reappointment/Promotion Instructions). [Online]. Available: http://www.rutgers.edu/oldqueens/instruct .doc

H.R. Varian. 1997. The future of electronic journals: Some speculations about the evolution of academic electronic publishing. Paper presented at the Scholarly Communication and Technology Conference, Emory University, Atlanta, GA, April 1997. [Online]. Available: http://arl.cni.org/scomm/scat/varian.html

S. Whisler. 1997. The economic realities of journal publishing. Newsletter on Serials Pricing Issues. 172.3 [Online]. Available: http://cadmus.lib.unc.edu/prices/1997/PR IC172.HTML\#172.3 [September 1997].

\section{LINKS FROM THIS ARTICLE}

1999-2000 Academic

Reappointment/Promotion Instructions 
http://www.rutgers.edu/oldqueens/instruct . doc

American Journal of Mathematics

http://muse.jhu.edu/journals/american_jo urnal_of_mathematics/

American Journal of Science

http://love.geology.yale.edu/ ryr/ajs/html

A. Dixon. Faculty publishing and the academic community: A publisher's perspective

http://tiepac.portlandpress.co.uk/books/on line/tiepac/session1/ch.2.htm

Electronic Journal of Differential Equations

http://ejde.math.swt.edu/

Elsevier Science

http://www.elsevier.nl/

Florida Agricultural \& Mechanical University

http://www.famu.edu/

Florida Atlantic University

http://www.fau.edu/

Florida Board of Regents 2000

http://www.borfl.org/univ_info/unitour.as

$\mathrm{p}$

Florida Gulf Coast University

http://www.fgcu.edu/

Florida International University

http://www.fiu.edu

Florida State Universiy

http://www.fsu.edu/

R. Kling and L. Covi. Electronic journals and legitimate media in the systems of scholarly electronic journals http://www.ics.uci.edu/ kling/klingej2.ht $\underline{\mathrm{ml}}$

Kluwer Academic Publishers

http://kapis.www.wkap.nl/kaphtml.htm/J $\underline{\text { RNLHOME }}$

V.H. Resh. Science and communication: An author/editor/user's perspective on the transition from paper to electronic publishing

http://www.library.ucsb.edu/istl/98-

summer/article3.html

Taylor \& Francis

http://www.taylorandfrancis.com

University of Central Florida

http://www.ecf.edu/

University of Florida

http://www.ufl.edu/

University of North Florida

http://www.unf.edu/

University of South Florida

http://www.usf.edu/

University of West Florida

http://www.uwf.edu/

H.R. Varian. The future of electronic journals: Some speculation about the evolution of academic electronic publishing

http://arl.cni.org/scomm/scat/varian.html

S. Whistler. The economic realities of journal publishing

http://cadmus.lib.unc.edu/prices/1997/PR

IC172.HTML@172.3

Wiley Interscience

http://www3.interscience.wiley.com/cgi-

bin/browsepj 
Artigo a nterio mente public ado no:

The J oumal of Elec tronic Publishing December, 2000 Volume 6, Issue 2 ISSN-1080-2711

http://www.press.umich.edu/jep/0 6-02/sweeney.html Autoriza do pelo a utore o Editor do periódico acima a ser public a do na Rev. Online Bibl. Prof. J oel Martins 